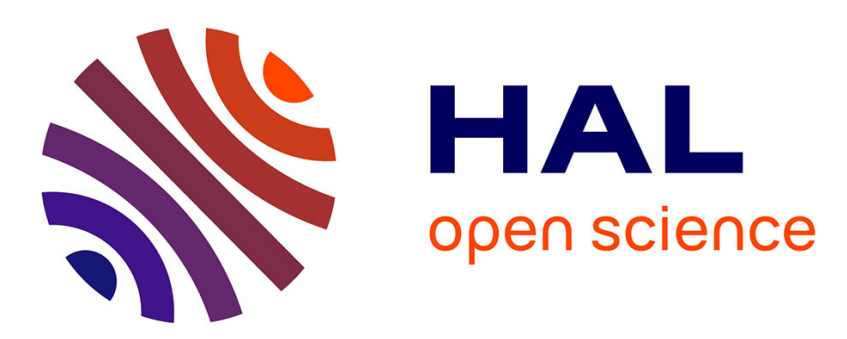

\title{
Characterisation and modelling of aging of composites
}

Julien Mercier, Anthony R. Bunsell, Philippe Castaing, Jacques Renard

\section{To cite this version:}

Julien Mercier, Anthony R. Bunsell, Philippe Castaing, Jacques Renard. Characterisation and modelling of aging of composites. Matériaux 2006, 2006, Dijon, France. 8 p. hal-00144507

\section{HAL Id: hal-00144507 \\ https://hal.science/hal-00144507}

Submitted on 3 May 2007

HAL is a multi-disciplinary open access archive for the deposit and dissemination of scientific research documents, whether they are published or not. The documents may come from teaching and research institutions in France or abroad, or from public or private research centers.
L'archive ouverte pluridisciplinaire HAL, est destinée au dépôt et à la diffusion de documents scientifiques de niveau recherche, publiés ou non, émanant des établissements d'enseignement et de recherche français ou étrangers, des laboratoires publics ou privés. 


\title{
CHARACTERISATION AND MODELLING OF AGING OF COMPOSITES
}

\author{
Julien Mercier*, Anthony Bunsell*, Philippe Castaing**, Jacques Renard* \\ * Centre des matériaux P.M. Fourt UMR CNRS 7633 BP87 91003 EVRY Cedex \\ e-mail : julien.mercier@ensmp.fr , anthony.bunsell@ensmp.fr, jacques.renard@ensmp.fr \\ ** CETIM Nantes, 74 route de la Jonelière BP82617 44236 NANTES Cedex3 \\ e-mail : philippe.castaing@cetim.fr
}

\begin{abstract}
The aim of this study was to better understand the aging of glass fibre-epoxy composites exposed to humid conditions and loading so as to predict its effects on the lifetimes of composite structures. Water diffusion in the material was initially determined by gravimetric methods under different conditions of relative humidity (r.h.) conditions. A fickian model of diffusion could describe the results obtained. The specimens, saturated at different levels, were mechanically characterised and tensile strengths and shear moduli were seen to decrease with water uptake. The effects of matrix cracking of the laminate on water absorption and its mechanical properties have also been studied. Differences between reversible and irreversible changes in properties were revealed and analysed in detail. A predictive model has been proposed by considering different sections throughout the thickness of the material. As a first step in modelling the diffusion process, the non-uniform water distribution across the composite for any conditions (temperature, humidity, aging time) are determined. The resulting mechanical properties of the material, as a function of the absorbed water concentration, are determined in each point. The model which is proposed enables the global behaviour of composite to be determined, at all stages of water absorption and matrix cracking, by calculating behaviour in each section of the composite through its thickness.
\end{abstract}

Keywords : Composite, Aging, Cracking, Damage, Modelling.

\section{INTRODUCTION}

Composite materials composed of anorganic matrix reinforced with glass fibres are sensitive to water absorption. Environmental ageing, including humidity and temperature as well as mechanical loading, leads to material degradation. There is therefore a need for a better understanding of the evolution of material properties during aging, in order to predict lifetimes or mechanical properties at any given time. Degradation may well occur but if it is understood and its rate known, the material can still be used within certain limits, just as are other more traditional materials.

Water absorption is generally experimentally determined by gravimetric methods [1,2] and various diffusion models are used to describe the moisture-sorption kinetics [3]. The Fickian diffusion model is widely used in the case of aging in humid conditions. A consequence of the aging is, for example, a decrease of mechanical properties (stiffness, strength at rupture...) [1$2,5-8]$. This can be explained by changes in the matrix and degradation of the glass fibre/matrix interface. It is however important to differentiate reversible from irreversible changes. On drying, the effects of water uptake, including weight change, are reversible even if significant modifications to the composite characteristics are observed during aging. Reversibility can be lost if aging conditions are more severe and if damage occurs during this phase. In order to correctly evaluate composite behaviour it is necessary to include evaluation of micro cracking of cross ply laminates [10-11].

The present study initially involved determining the water uptake as well as desorption kinetics of unidirectional specimens under different humid conditions. Mechanical tests were then performed in order to determine the evolution of different parameters as a function of water uptake. Then the damage kinetics were investigated for laminates under different conditions. Finally a finite element model which allows the material properties to be predicted at any time, during aging, was developed and is proposed here. 


\section{MATERIALS AND METHODS}

\section{1- Materials}

The material studied was an epoxy matrix reinforced with E-glass fibres. The matrix was a DGEBA epoxy resin (LY5052) associated with a diamine hardener (HY5052). The unidirectional (UD) specimens and the laminates were produced using UD prepreg processed by moulding.

\section{2- Moisture sorption measurement}

Moisture-sorption of composite was investigated using composite plates $100 \mathrm{~mm}$ wide, $100 \mathrm{~mm}$ long $[1,2,5]$ and with different thickness. They were post-cured for $5 \mathrm{~h}$ at $110^{\circ} \mathrm{C}$ then aged in different conditions :

- Different conditions of relative humidity $(30 \%, 62 \%, 75 \%$ et $100 \% \mathrm{HR})$ at $40^{\circ} \mathrm{C}$ and $60^{\circ} \mathrm{C}$ for $1 \mathrm{~mm}$ thick specimens.

- Immersion in distilled water at 40 and $60^{\circ} \mathrm{C}$ for different thicknesses $(1,2,4,8 \mathrm{~mm})$.

- Drying and re-sorption of all these specimens.

During aging, the specimens were periodically weighed with an METTLER AT250 electronic balance (precision $0.01 \mathrm{mg}$ ). The percent mass increase was calculated as :

$$
\mathrm{M}_{\mathrm{t}}(\%)=\frac{\mathrm{W}_{\mathrm{t}}-\mathrm{W}_{0}}{\mathrm{~W}_{0}} .100
$$

where $W_{t}$ is the weight of the wet sample at time $t$ and $W_{0}$ is the original weight of the dry sample.

\section{3- Tensile tests}

To determine changes of many mechanical parameters as a function of aging time, tensile tests were conducted on the unidirectional specimens saturated under different relative humidity conditions. The two different orientations $90^{\circ}$ and $45^{\circ}$ (i.e. orientations of fibres compared to those in the tensile load direction) were analysed. The fibres were considered to be insensitive to the aging and therefore the elastic modulus parallel to the fibre direction would be unaffected by ageing. The tensile tests were performed at room temperature using an Instron tensile testing machine, at $0.05 \mathrm{MPa} / \mathrm{s}$. An extensometer was used to measure longitudinal extension and a strain gauge for transverse extension.

\section{4- Intralaminar micro cracking experiments and analysis}

The aim of this part of the study was to analyse material damage due to mechanical loading and more precisely intralaminar cracking $[5,10]$. Tensile tests on UD specimens, produced no matrix cracking, failure occurring with no prior macroscopic warning. However cross plied laminates such as those examined in this study with stacking sequences of $\left(0_{2} / 90_{n} / O_{2}, n=2,4\right.$ or 6) did show matrix cracking on loading. The density of cracks as a function of applied load (i.e. kinetic of cracking) was determined for both unaged and specimens aged in order to reveal the effects of water absorption on the damage kinetics. The edge of the specimens was continuously observed by optical microscopy and a camera, as indicated in figure1. The loading was periodically interrupted (at steps of $50 \mathrm{MPa}$ ) to record the density of cracks in the $90^{\circ}$ plies.

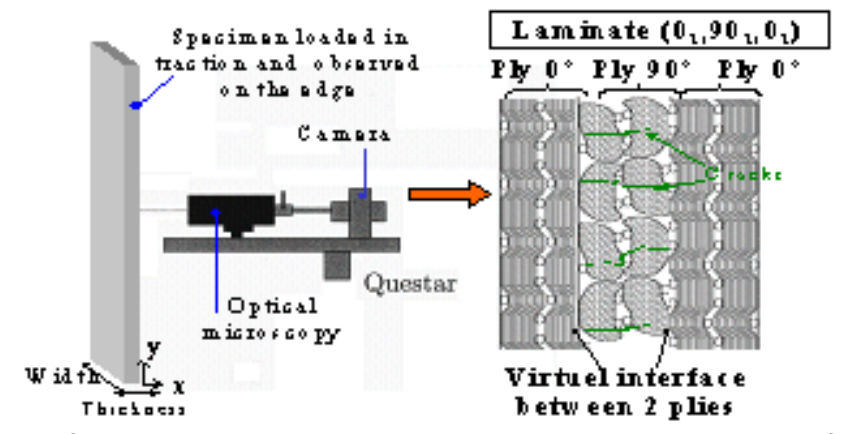

Fig. 1. Schematic view of crack density measurement and example of cracking for a $\left(\mathrm{O}_{2} / \mathrm{SO}_{4} / \mathrm{O}_{2}\right)$. 


\section{Results}

\subsection{Water-sorption kinetics}

3.1.1. Sorption in water vapour

The results shown in figure 2 give the amount of water uptake as a function of the square root of time, as is conventional, for all the humid air conditions. The smooth lines are fits considering unidirectional Fickian diffusion as detailed elsewhere [5] and the parameters $M_{s}$ and $D$ were determined for each curve. All results found for the two temperatures are given in the table.

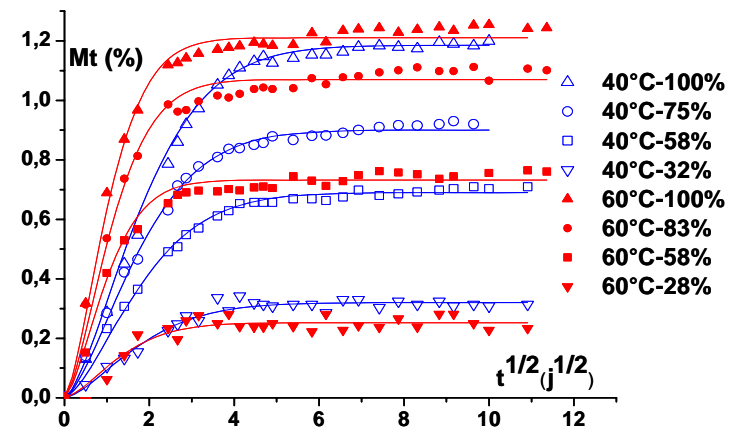

\begin{tabular}{ccll}
\hline Temperature & r.h.(\%) & \multicolumn{1}{c}{ Msat (\%) } & \multicolumn{1}{c}{ D ( mm $\left.\mathbf{m}^{\mathbf{2}} \mathbf{s}^{-1}\right)$} \\
\hline \multirow{3}{*}{$40^{\circ} \mathrm{C}$} & $100 \%$ & $1,21 \pm 0,02$ & $(2 \pm 0,05) \cdot 10^{-7}$ \\
& $75 \%$ & $1,03 \pm 0,07$ & $(2,2 \pm 0,2) \cdot 10^{-7}$ \\
& $68 \%$ & $0,74 \pm 0,03$ & $(2,1 \pm 0,01) \cdot 10^{-7}$ \\
& $32 \%$ & $0,33 \pm 0,02$ & $(2,3 \pm 0,2) \cdot 10^{-7}$ \\
\hline \multirow{3}{*}{$60^{\circ} \mathrm{C}$} & $100 \%$ & $1,26 \pm 0,01$ & $(7,5 \pm 0,5) \cdot 10^{-7}$ \\
& $75 \%$ & $1,1 \pm 0,03$ & $(8 \pm 0,5) \cdot 10^{-7}$ \\
& $68 \%$ & $0,75 \pm 0,03$ & $(7,7 \pm 0,7) \cdot 10^{-7}$ \\
& $32 \%$ & $0,29 \pm 0,02$ & $(7,8 \pm 0,7) \cdot 10^{-7}$ \\
\hline
\end{tabular}

Fig. 2. Moisture absorption curves of 1D specimens exposed to humid air. Mt= weight change (\%). Symbol : data; line : Fickian fit for unidirectional diffusion. Values of maximum moisture content $M_{\text {sat }}$ and diffusivity $D$ in the table.

The behaviour of the material exposed to humid conditions shows excellent correspondence with the classical diffusion model. The effects of temperature and relative humidity are seen to confirm previous studies [1-2]: Temperature was seen to accelerate water diffusion and D was seen to obey an Arrhenius type relationship $D=614 . \exp (-13511 / R T)$. This means that the initial absorption was four times quicker at $60^{\circ} \mathrm{C}$ than at $40^{\circ} \mathrm{C}$. The saturation levels, however, were observed to be independent of temperature and only to depend on relative humidity, such that $\mathrm{M}_{\mathrm{s}}=0.004 .(\mathrm{HR})^{1.25}$.

\subsection{2- Sorption in immersion}

Water uptake during immersion at $60^{\circ} \mathrm{C}$ for different thicknesses are given elsewhere [5]. Only an example is plotted in Figure 3(b), for a $1 \mathrm{~mm}$ thick specimen. Saturation was not observed after one year of immersion, rather a continuing increase in water uptake was seen. This observed behaviour indicated that immersion in water produced irreversible damage which progressed with time and water uptake. The effect was in addition to the Fickian behaviour. By complementary analysis, the continuing increasing water uptake was therefore seen not to be due to matrix cracking but rather to interfacial debonding [5].

\section{2- Reversibility of the absorption process : drying and reabsorption kinetics}

In order to investigate if the absorption process was reversible, the specimens were dried and the kinetics of drying followed by a second sorption cycle were determined.

\subsection{1- Case of aging in humid air}

An example is given in figure $3(\mathrm{a})$ for UD material aged at $60^{\circ} \mathrm{C}-100 \%$ r.h., followed by drying at $60^{\circ} \mathrm{C}$ and then a second aging cycle at $60^{\circ} \mathrm{C}-100 \%$ r.h. Similar absorption kinetics were seen for all three stages of absorption and drying. The saturation weight gain was the same for the first and the second aging cycles and the results for the three stages could be fitted with a similar diffusion constant $\mathrm{D}$. This confirmed that the material appeared not to be damaged by aging in humid air.

\subsection{2- Case of aging in immersion}

An example is given in figure 3(b) for specimens aged in immersion at $60^{\circ} \mathrm{C}$ for 191 days followed by drying at $60^{\circ} \mathrm{C}$ and a second cycle of immersion. After the drying stage, the initial weight was recovered showing that leaching did not occur. However, the drying and the reabsorption stages were faster than the first water uptake stage (30\% to $40 \%$ quicker). This indicated, in contrast to aging in humid air, that the composite had been irreversibly modified. 
Complementary tests, in particular DMA analyse, revealed that the continuing increasing water uptake was not to be due to matrix cracking but rather to interfacial debonding, which is taken to be the irreversible damage provoked during immersion [5].

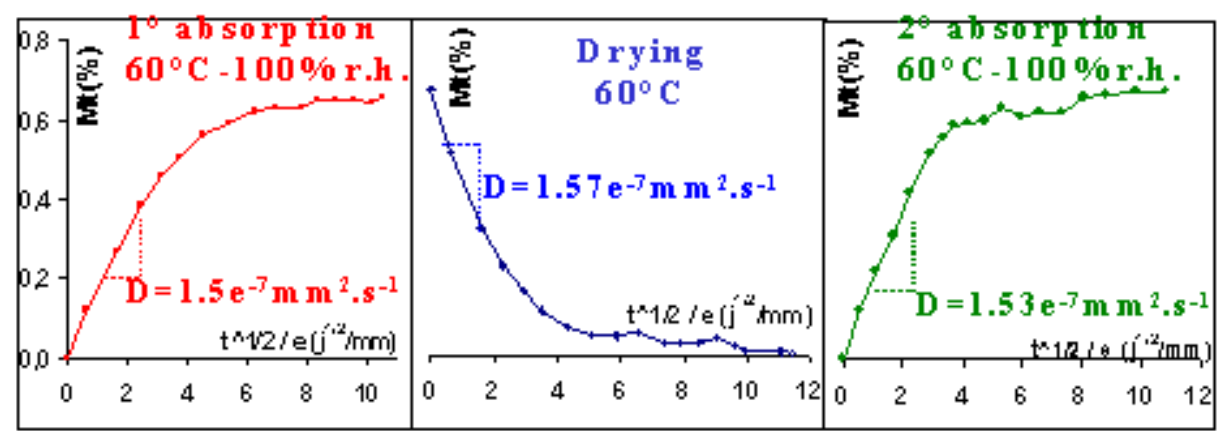

Fig. 3.a Kinetics for first absorption, drying and second absorption at $60^{\circ} \mathrm{C}-100 \%$ r.h.

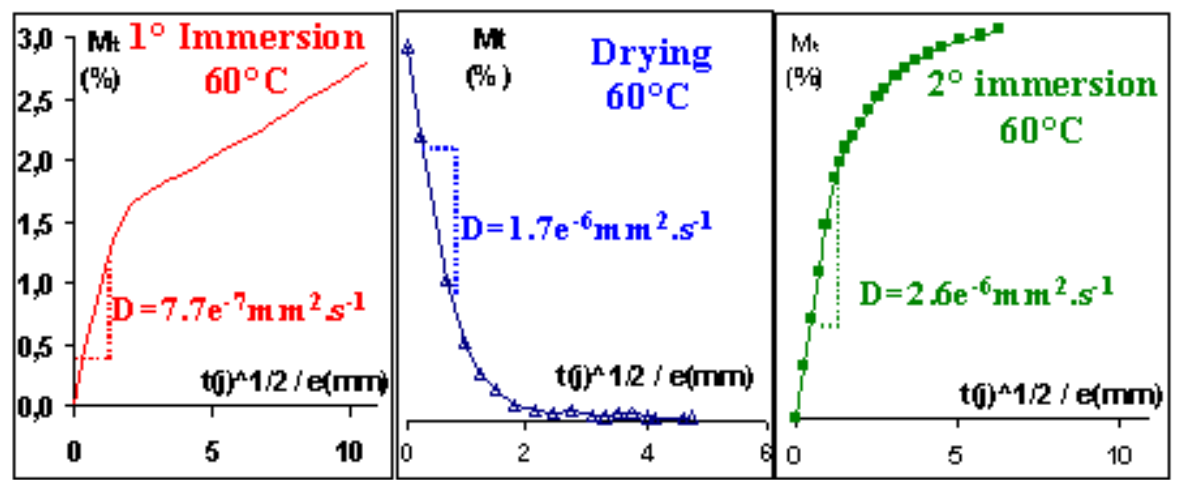

Fig. 3.b Kinetics for first absorption, drying and second absorption in immersion at $60^{\circ} \mathrm{C}$.

\section{3- Tensile tests}

3.3.1- Effects of ageing on mechanical properties

Tensile failure strength, transverse modulus $E_{t}$ (with $90^{\circ}$ specimen) and shear modulus $G_{12}$ (with $45^{\circ}$ specimen) were determined for each test. The results obtained are given in Figure 4. A considerable fall in strength and modulus was seen with water uptake. The decrease is around the same for the two temperatures and can reach $45 \%$ for the greatest water uptake. 

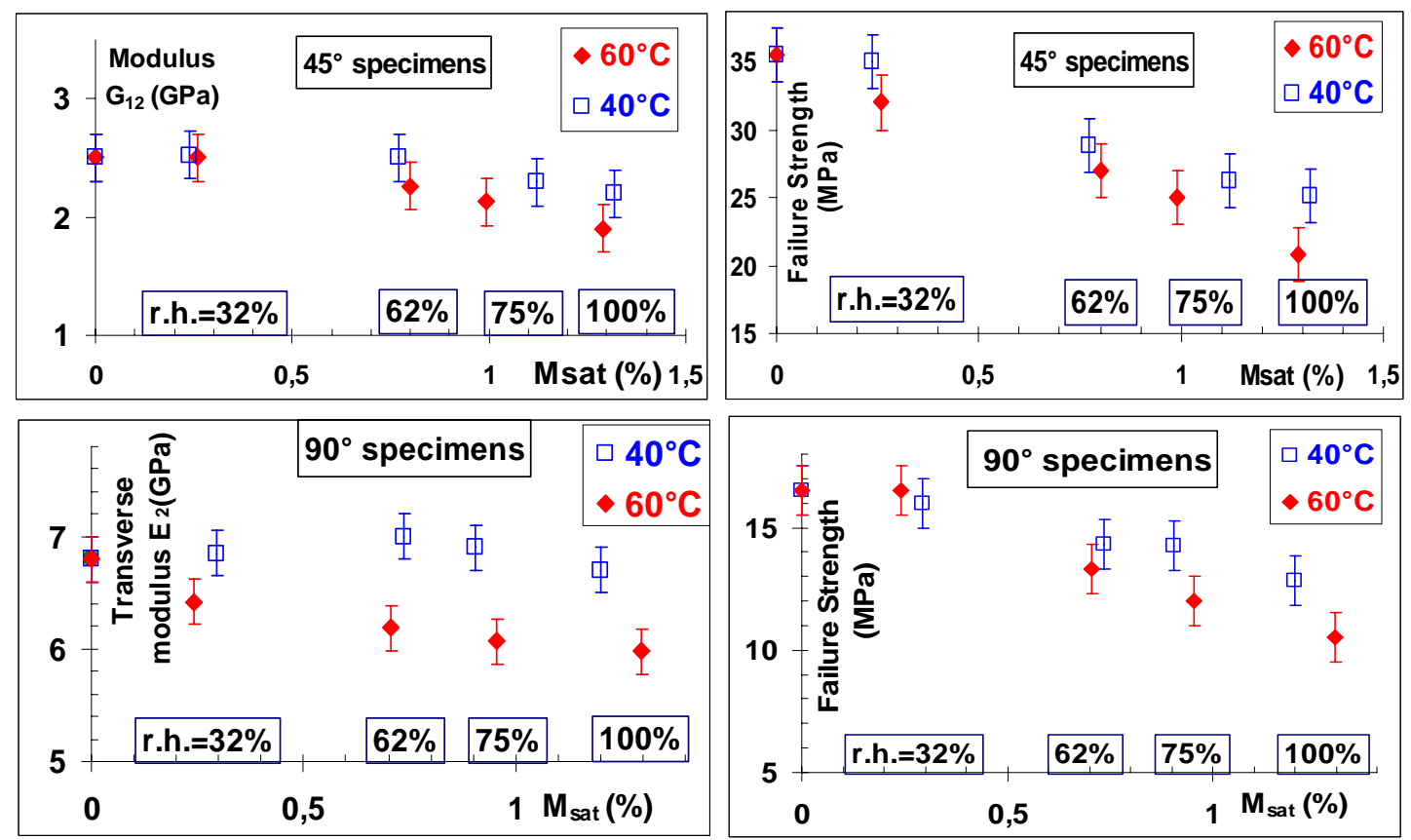

Fig. 4. Failure strength, transverse modulus $E_{t}$ and shear modulus $G_{12}$ as a function of water uptake at saturation.

\subsection{2- Specimens aged and dried}

Similar experiments were repeated for specimens aged until saturation and then dried. It was found that properties of the aged and dried material were the same as those of the received specimens (less than $4 \%$ of difference). It seemed that changes in the mechanical properties were reversible in both humid air and in immersion.

\section{5- Intralaminar micro cracking results}

\subsection{1- Characteristics of induced damage}

A group of parallel cracks, parallel to the fibres, occurred in plies orientated at an angle to the loading direction (plies at $90^{\circ}$ in this case), as shown in figure 1 . The crack density increased progressively with load, as shown in figure 5 for a $0_{2} / 90_{n} / 0_{2}$ laminate. No crack was observed up to an applied stress of $150 \mathrm{MPa}$ but above this level crack density increased until a limit, which was reached before failure, at around $350 \mathrm{MPa}$. Crack spacing was seen to be quite regular with distances between cracks being $0.5 \pm 0.2 \mathrm{~mm}$.

\subsection{2- Kinetics of cracking}

The kinetics of cracking were determined for the $\left(0_{2} / 90_{n} / 0_{2}\right)$ laminates. The curve $d=f(\sigma)$ has been plotted for each specimen, with $d=c r a c k$ density (number of cracks $/ \mathrm{mm}$ ) and $\sigma$ the applied load.

Unaged material: Results are given in figure 5 (left). The same damage kinetics were observed for the three thicknesses of $90^{\circ}$ plies, as described above.

Aged material : No cracks were observed, by optical microscopy, to have been initiated during aging. The kinetics of cracking for the $\mathrm{O}_{2} / \mathrm{gO}_{4} / \mathrm{O}_{2}$ laminates, unaged and saturated at $60^{\circ} \mathrm{C}$ $100 \% \mathrm{HR}$, are given in figure 5 (right). Similar results were obtained for the two conditions. 

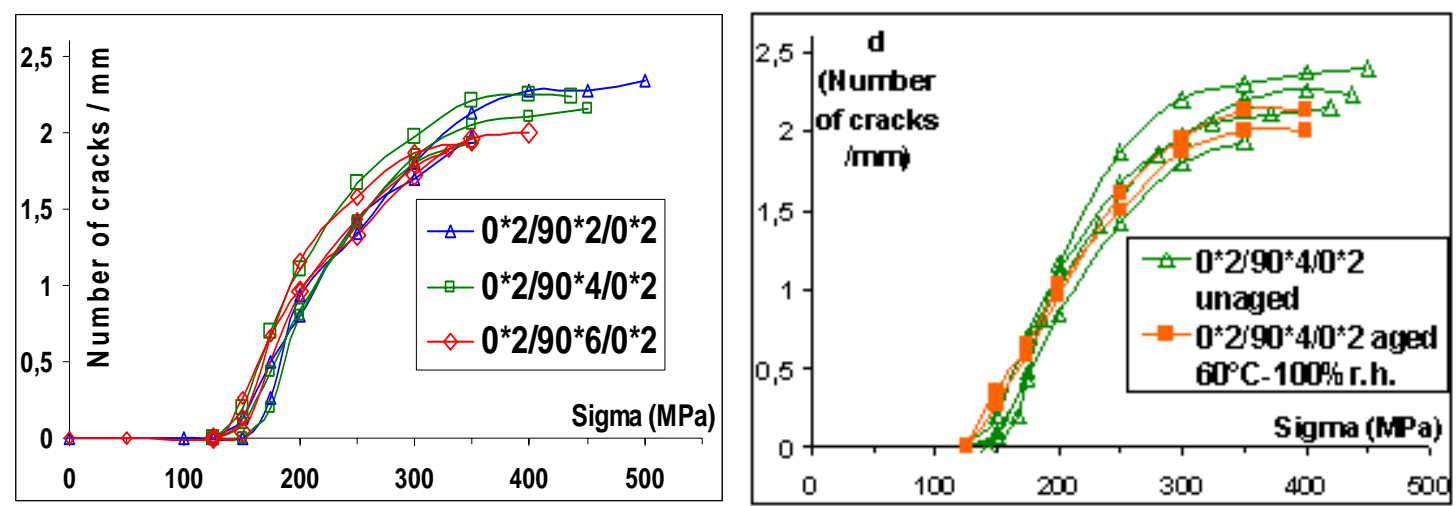

Fig. 5. Crack density (number of cracks crossing $90^{\circ}$ ply $/ \mathrm{mm}$ ) during loading for unaged $\mathrm{O}_{2} / 9 \mathrm{O}_{2} / \mathrm{O}_{2}, \mathrm{O}_{2} / 9 \mathrm{O}_{4} / \mathrm{O}_{2}$ and $\mathrm{O}_{2} / 9 \mathrm{O}_{6} / \mathrm{O}_{2}$ sequences (left) and comparison between unaged and aged (specimen saturated at $60^{\circ} \mathrm{C}-100 \% \mathrm{HR}$ ) $\mathrm{O}_{2} / 9 \mathrm{O}_{4} / \mathrm{O}_{2}$ sequence (right).

\section{6- Material cracked then aged}

The influence of damage, created by mechanical loading, on water absorption is analysed here. Specimens of $\mathrm{O}_{2} / 9 \mathrm{O}_{\mathrm{n}} / \mathrm{O}_{2}$ laminates were loaded until $350 \mathrm{MPa}$ then completely unloaded. The induced cracks were clearly not repaired during unloading Their effect on water absorption was studied under two conditions which were humid air at $60^{\circ} \mathrm{C}-100 \% \mathrm{RH}$ and immersion at $60^{\circ} \mathrm{C}$. The comparison between the water uptake of initially undamaged material and the damaged material showed no significant difference [5]. The presence of cracks has no discernible effect on water uptake in the unstressed laminate.

\section{HYDRO-MECHANICAL SIMULATION AND PREDICTION OF MATERIALS PROPERTIES}

An original method has been developed in order to predict the properties of a composite material which has not yet reached equilibrium with the surrounding humid environment. Calculations are made with the finite element software Zset.

\section{1- Water diffusion modelling}

The first step consists in modelling water diffusion through the material. Thickness, diffusivity into material and humid boundary conditions on each face ( $\left.C^{\text {surf }}\right)$ have to be introduced. Fick's law is first considered. As a result of the calculation, the value of water concentration $C$ is given at each point or node of the structure and the profile of water concentration through the thickness can be plotted. An example is given in figure 6 for a $2.15 \mathrm{~mm}$ thick virtually aged at $60^{\circ} \mathrm{C}-100 \%$ r.h. Diffusion occurs only in one direction in this case but $2 \mathrm{D}$ or $3 \mathrm{D}$ cases can be treated. $C^{\text {surf }} \neq 0$ have to be imposed on the others faces.
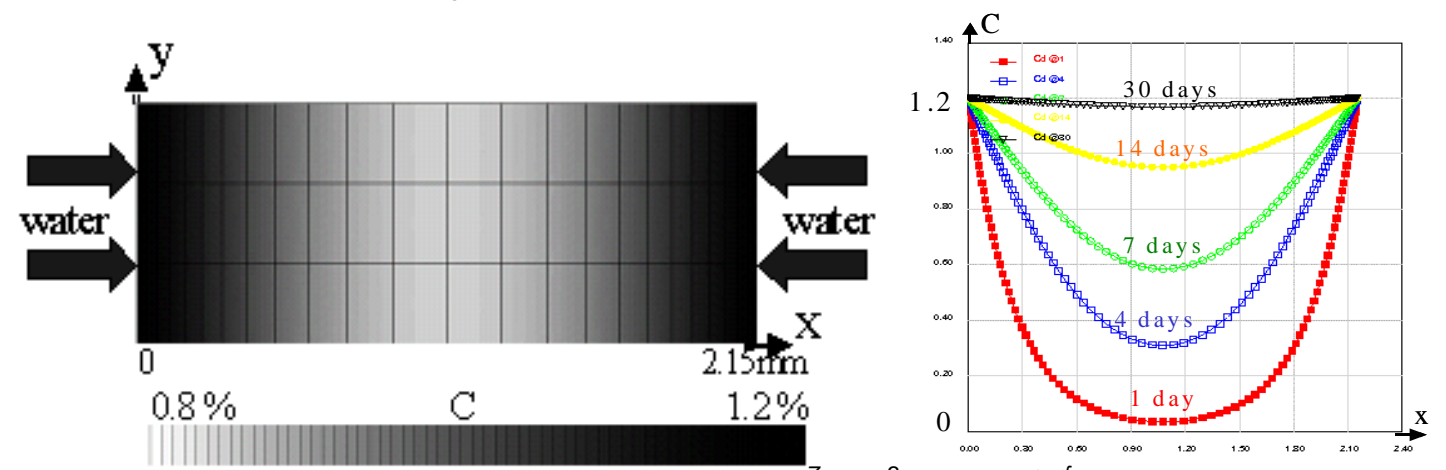

Fig.6. Simulated water $1 D$ diffusion with $D=7.5 \times 10^{-7} \mathrm{~mm}^{2} / \mathrm{s}$ et $C^{\text {surf }}=1.2 \%$ (corresponding to aging at $60^{\circ} \mathrm{C}-100 \%$ r.h.) for a $2.15 \mathrm{~mm}$ thick specimen.. (a) Map of the variable $C$ at 10 days of aging; (b) water concentration profile for different aging times.

\section{2- Mechanical test modelling}

Knowing the initial rigidity $C^{0}$ of the material, the objective is to determine the rigidity $C$ of a structure subjected to aging and mechanical loading, following equation (2). 
$\mathrm{C}=\mathrm{C}^{0}-\underbrace{\mathrm{C}^{\mathrm{H}} \cdot \mathrm{C}_{\mathrm{w}}}_{\text {Decrease of rigidity due }}-\underbrace{\mathrm{f}(\mathrm{d}) \cdot \mathrm{C}^{\mathrm{F}}}_{\text {Decrease of }}$

with :

$\mathrm{C}_{\mathrm{w}}$ : water concentration in the material (\%).

$\mathrm{d}$ : density of cracks $\left(\mathrm{mm}^{-1}\right)$, which is representative of the damage of the material.

$\mathrm{C}^{\mathrm{H}}$ et $\mathrm{C}^{\mathrm{F}}$ matrix representative of decrease of properties due to respectively humidity and cracking.

The two components which contribute to a decrease of rigidity can be considered together or separately but are non coupled according to the experiments. The variable $d$ takes into account damages of different origins, i.e. damage induced by aging and/or damage induced by mechanical loading. Some parameters have been identified using experimental results presented above. Concerning water-dependence properties, knowing the relations rigidity $=f\left(C_{w}\right)$ determined experimentally (see part 3.3), different rigidities are assigned to each point, directly depending on the local water concentration determined by the diffusion model. Then a simulated tensile test enables the global properties of composite to be determined from the local properties in each section. The model being identified for a particular stacking sequence and aging conditions, it is then possible to follow the evolution of rigidity and damage (by the variable d) during aging and/or mechanical loading. Some examples are given in the following figures. In figure 7.a are represented the maps of the crack density $d$ at different traction loading levels, for a $\mathrm{O}_{2} / 90_{4} / \mathrm{O}_{2}$ sequence. As observed in experiments, only the plies at $90^{\circ}$ (in the middle of the structure) in which $d$ increases during loading, are damaged. In figure 7.b are plotted the evolution of the longitudinal modulus $\mathrm{E}$ as a function of the applied load, for unaged, aged at $60^{\circ} \mathrm{C}-100 \%$ r.h. and aged in immersion $0_{2} / 90_{2} / 0_{2}$ material, with a comparison between experimental (Exp.) and theoretical results (Th.). The results agree well.

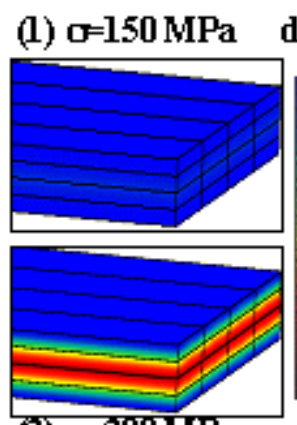

(3) $\mathrm{c}=300 \mathrm{MPa}$

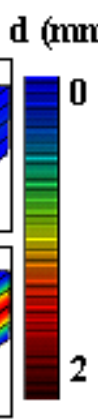

2

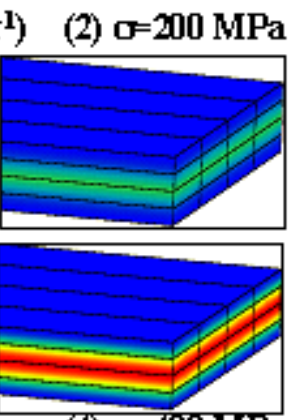

(4) $\mathrm{G}=400 \mathrm{MPa}$

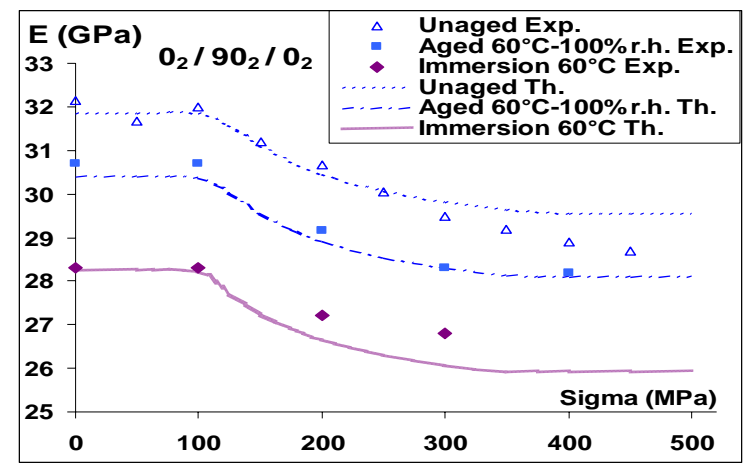

Fig.7.b. Evolution of the global longitudinal modulus as a function of applied load for laminates, both unaged, aged in $60^{\circ} \mathrm{C}-100 \%$ r.h. and aged by immersion.

\section{CONCLUSIONS}

The effects of hygrothermal ageing on many mechanical properties have been studied. A reversible decrease in rigidity due to humidity and an irreversible change due to cracking due to mechanical loading are seen to be independent. A numerical model, which takes into account all the experimental conclusions, is then proposed. It is possible to predict hygrothermo-mechanical degradation at all times during water absorption during which the water concentration profile is not uniform within the material. This can be carried out for any other staking sequence of the 1D or laminate composite of any thickness, at any temperature and humidity and at any loading level. It is then possible to optimize the thickness of a structure to obtain a given wanted lifetime in any given conditions. 


\section{ACKNOWLEDGEMENTS}

This work was supported by the CETIM of Nantes. The authors wish to thank Bretagne Composite for providing the material. Many thanks are also due to the technicians of the Material Center for their experimental support and to A. Thionnet for his modelling support.

\section{REFERENCES}

1. Bonniau, P., Bunsell, A.R., "A comparative study of water absorption theories applied to glass epoxy composites", J. Composite materials, 15 (1981).

2. Dewimille, B., Bunsell, A.R., "Vieillissement hygrothermique d'un matériau composite fibres de verre - résine époxyde", Annales des composites, 1 (1982).

3. Carter, HG., Kibler, KG., "Langmuir-type model for anomalous moisture diffusion in composite resins", Journal of Composite Materials 12 (1978).

5. Mercier, J., Bunsell, A., Castaing, P., Renard, J., "Caractérisation et modélisation du vieillissement de matériaux composites", Revue des composites et des matériaux avancés 84 (2005) 189-219.

6. Ghorbel, I., Mécanismes d'endommagement des tubes verre-résine pour le transport d'eau chaude", PhD Thesis, ENSMP, 1990.

7. Lévêque D, Schieffer A., "Analyse multiéchelle des effets du vieillissement sur la tenue mécanique des composites à matrice organique", Revue des composites et des matériaux avancés, 12 (2002).

8. Weitsman, YJ., Guo Ya-J., "Correlation between fluid-induced damage and anomalous fluid sorption in polymeric composites". C. Sc. \& Technology 62 (2002).

9. Zhou, J., Lucas, J., "Hygrothermal effects of epoxy resin. Part I: nature of water in epoxy", Polymer 40 (1999).

10. Renard, J., Favre, J-P., Jeggy, T., "Influence of transverse cracking on ply behavior: introduction of a characteristic damage variable", Composites Science and Technology 46 (1993) 29-37.

11. Perreux, D., Suri, C. "A study of the coupling between the phenomena of water absorption and damage in glass/epoxy composite pipes", Composites Science and Technology 57 (1997) 1403-1413. 